\title{
Relationships between perception of illness, social support and hemodialysis adequacy
}

\begin{abstract}
Introduction. The patients in situations of "being ill" have to face not only pain and disabilities, but also problems in their social relationships. Perceptions of illness are results of reactions to the changes in the existential situations, and that these correspond to determined illness coping strategies.

Aim. The aim of the research was to determine the relationships between perception of illness and social support, with the indicators of the adequacy of the renal replacement treatment and the level of urea as a biomarker of disease offset.

Material and methods. The study was conducted on a group of 150 patients who were on chronic hemodialysis, and who were suffering from end stage renal disease. The patients were treated at on of the several Fresenius Medical centres. As a group, average $\mathrm{Kt} / \mathrm{V}$ value was $1.45(\mathrm{SD}=0.22)$ and the $\mathrm{URR}$ ratio $71.78(\mathrm{SD}=5.95)$. Moreover, average urea concentration before $\mathrm{HD}$ equaled to $133.78 \mathrm{mg} \%(\mathrm{SD}=39.68)$ and after hemodialysis $-38.22 \mathrm{mg} \%(\mathrm{SD}=14.60)$. The research procedure was based on a questionnaire study. This applied three standardized scales: the Imagination and Perception of Illness Scale (IPIS), the brief Illness Perception Questionnaire (IPQ-Brief) and the Berlin Social Support Scale (BSSS).

Results. Patients who exhibited higher values of urea concentration in the blood serum measured before HD, perceived their disease (IPIS scale) as causing more motivation loss to carrying out specific activities, as well as mental and physical sphere destruction, pessimism and lost control over the disease. What is more, higher values of urea reduction ratio (URR) positively correlate with the loss of control over the disease $(r=-0.20, p=0.024)$. Moreover, patients characterized by higher values of urea concentration in the blood serum before hemodialysis, evinced greater need for social support (BSSS).

Conclusions. The need for social support among ESRD patients treated by hemodialysis does not correlate with dialysis adequacy indicators. Furthermore, the level of urea marked before hemodialysis exhibits an interdependence with psychological determinants of illness perception and social support.
\end{abstract}

Keywords: perception of illness, social support, end stage renal disease, hemodialysis.

DOI: $10.1515 /$ pjph-2015-0002

\section{INTRODUCTION}

Patients maintained on chronic hemodialysis, in end stage renal disease (ESRD), experience limitations caused by the disease and the type of applied treatment. The situation of being affected by such a disease is a phenomenon difficult to endure. This also has influence upon, and alters the social environment in which the patient functions. The patient in a situation of being diseased has to face not only pain and psycho-physiological ailments, but also problems in their social relationships. Stressors affecting the patients include restrictions in daily functioning, financial and dietetic constrains, possible terse relations with medical personnel and with the patients' family, as well as difficulties in their professional situation [1]. In the field of research dealing with the diverse psycho-social factors modifying the negative impact of stressors on the lives of patients on hemodialysis, attention is drawn to the patients' perception of their disease and their obtaining of social support. Estimating the positive influence of these psychosocial variables enables researchers to ascertain the interdependence between them, the biomarkers of the disease and the adequacy of treatment.

Perception of ones' own disease by patients with ESRD who are maintained on hemodialysis, has been the subject of much recent research [2-5], including several current prospective studies [6]. Yet, only a few reports describe the relationship between patients' perception of ESRD, and the indicators of HD adequacy and mortality rates [7,8]. Assuming that the perception of ones' own illness is a result of reaction to the changes in the existential situation, and that this corresponds to determined illness coping strategies, an essential research task is to ascertain the social support that a patient receives. In literature drawn from the field of health psychology, the category of social support is defined

\footnotetext{
${ }^{1}$ Department of Ethics and Human Philosophy, Medical University of Lublin, Poland

${ }^{2}$ Chair and Department of Nephrology, Medical University of Lublin, Lublin, Poland

${ }^{3}$ Fresenius Nephrocare Polska Sp. z o.o. Poznań, Poland
} 
in two aspects - with respect to its structural and to its functional natures [9]. With regard to the structural aspect, social support is determined on the basis of the degree of involvement of the person inside the structure of a social relationship. As to the functional aspect of social support, this term is utilized by researchers in reference to an analysis of the function that the supportive interactions play in the relationships between the person and his/her interpersonal contacts. Perceived available social support is, hence, a subjective assessment of the availability of support, and the acceptance and appreciation of the respondents by others in the context of interpersonal relationships [9]. In recent years, social support received by patients maintained on HD in the course of ESRD, has undergone study [10,11] and meta-analysis [12]. However, there has been no assessment of the relationship between social support and the indicators of adequacy, and renal replacement therapy.

\section{AIM}

The aim of the conducted research was to determine the relationship between perception of illness and social support, with the indicators of the adequacy of the renal replacement treatment and the level of urea as a biomarker of disease offset.

\section{MATERIAL AND METHODS}

The study was conducted on a group of 150 patients on chronic hemodialysis suffering from end stage renal disease. The patients were treated at one of the several Fresenius Medical centres. The group consisted of 67 woman and 83 men. Of these, 85 were village dwellers, while 65 were city dwellers. The respondents were aged between 30 and 87 , average age being $64.04(\mathrm{SD}=12.57)$. Of the study group, average $\mathrm{Kt} / \mathrm{V}$ value was $1.45(\mathrm{SD}=0.22)$ and the $\mathrm{URR}$ ratio was $71.78(\mathrm{SD}=5.95)$. Moreover, average urea concentration before $\mathrm{HD}$ equaled to $133.78 \mathrm{mg} \%(\mathrm{SD}=39.68)$, and after hemodialysis $-38.22 \mathrm{mg} \%(\mathrm{SD}=14.60)$.

Every patient had their urea concentration measured on the day of the questionnaire study prior $(\mathrm{C} 0)$ and post $(\mathrm{C} 1)$ hemodialysis. The urea reduction rate (URR) and the dialysis dose $(\mathrm{Kt} / \mathrm{V})$ were also determined. The dialysis dose $(\mathrm{Kt} / \mathrm{V})$ was measured based on the Daugirdas method [13]. URR, as a method determining the effectiveness of dialysis, was made on the basis of the following formula: $\mathrm{URR}=(\mathrm{C} 0-\mathrm{C} 1) / \mathrm{C} 0$ - using the urea concentration before $(\mathrm{C} 0)$ and after $(\mathrm{C} 1)$ HD. Independent variables such as age, gender, education level and place of residence of the respondents, were also part of the analysis.

The research procedure was based on a questionnaire study. This applied three standardized scales: the Imagination and Perception of Illness Scale (IPIS), the brief Illness Perception Questionnaire (IPQ-Brief) and the Berlin Social Support Scale (BSSS)

The IPIS scale, constructed by Jarosław Sak [14], allows for expressing subjective meanings attributed by the patients to the disease. This tool uses the semantic differential technique. The IPIS scale is a questionnaire consisting of 32 opposing terms, and is designed to test the percep- tion of different disease entities and the general concept of the disease, among both healthy and unhealthy individuals. By way of assessing six factors, it allows for the understanding of patient's beliefs that are being held with respect to diverse aspects of disease perception. Among these are loss of motivation for targeted activities, destruction of the psychical sphere, destruction of the physical sphere, pessimism, reactions to their surroundings as caused by their disease and their loss of control over it. Because of the various number of items making up the individual components of the proposed IPIS scale, expressing the results are expressed in the form of an arithmetic mean calculated separately for each of the six indicators. The seven step scale of choice placed between opposing items is oriented in the following matter: " 0 " signifies the choice of maximally positive item attributed to the disease, whereas " 6 " signifies the opposite. The higher the result obtained within a given IPIS dimension, the more negative the perception on the disease through the prism of this factor. The overall result is calculated by summing up the average gained in the various components of this scale.

The Brief Illness Perception Questionnaire [15] was inspired by Leventhal's self-regulation model [16]. This model assumes that the image of the disease, which is formed in the mind of the patient, influences his or her "commonsense health behaviors". This influence is thought to be simultaneous with cognitive and emotional processes. BriefIPQ includes eight questions, each one making up a separate component of this scale. These are: the influence of the disease on the patients' life, the effect of excessive duration of the disease, the significance of controlling the disease, belief in the efficacy of the treatment, the effects brought about from the symptoms of the disease, the worry that accompanies it, the attempts made towards understanding it, as well as the negative impact of the disease on the emotional state. The answers are expressed by the respondents by way of the 11-point Likert scale - ranging from " 0 " to " 10 ".

The Berlin Social Support Scale [17] enables researchers to ascertain the functional aspect of social support, among others, in the context of factors determining the perceived emotional and instrumental available support, and the patients' need for social support.

The responses were assessed in a 4 point estimate scale. In order to analyze the obtained data, the correlation model was applied. Using the Pearson's product moment, a correlation was established between SF-36 and PSQI and controlled variables concerning the dose of dialysis: Kt/v, URR and urea concentration before $(\mathrm{C} 0)$ and after hemodialysis (C1). The differences between groups based on gender and place of residence was calculated by way of Student's $t$ test, with a level of significance being determined at $\mathrm{p}<0.05$. In the process of data analysis, the authors applied Statistica 10.0 PL.

\section{RESULTS}

Upon analyzing the correlations between dialysis parameters (Kt/V, URR), the urea level and perceptions of ones' own illness measured by way of the six factors of the IPIS scale, we observed statistically significant correlations, 
with a positive direction of correlation between urea concentration determined before hemodialysis ( $\mathrm{C} 0)$, and the five components of the IPIS scale. Patients who exhibited higher values of urea concentration in the blood serum measured prior to HD, perceived their disease as causing more motivation loss towards carrying out specific activities, as well as mental and physical sphere destruction. Connected to this were more intense feelings of pessimism and of having lost control over the disease. It was also found that higher values of urea reduction ratio (URR) positively correlates with feeling of having lost control over the disease $(r=0.20, p=0.024)$, while a higher concentration of urea after HD correlates with the patient perceiving his/her own illness through the prism of destruction of the psychical sphere $(r=0.36$, $\mathrm{p}=0.034)$ (Table 1).

Upon conducting an analysis of correlations between hemodialysis parameters (Kt/V, URR) and the level of urea, and self-perceptions of illness measured using the eight items of the Brief-IPQ, two statistically significant correlations were noted. The urea level before hemodialysis correlated negatively with the patient's conviction on controlling his/her disease $(\mathrm{r}=0.37, \mathrm{p}=0.028)$, while higher dialysis doses kt/V correlated positively with the patients' convic- tions on the negative influence of the disease on his/her emotional state $(\mathrm{r}=0.19, \mathrm{p}=0.036)$ (Table 2).

The analysis of the obtained matrix of correlation between hemodialysis parameters (Kt/V, URR) and the urea concentration, as well as the available social support and the need for this support as measured by the three components of the BSSS scale, revealed the presence of a another statistically significant correlation. Patients characterized by higher values of urea concentration in the blood serum before hemodialysis evinced greater need for social support (Table 3 ).

Finally, there were no statistically significant correlations between IPIS and BSSS scale items and the age and education of the patients. Moreover, an analysis of the gender of the respondents, revealed that no statistically significant data were obtained in either the perceiving of ones' own illness as measured by the IPIS scale, nor the social support as measured by the BSSS.

\section{DISCUSSION}

Previous researches on the perception of ones' own illness using diverse versions of the IPQ- scales which were inspired by the Leventhal self-regulation model, showed

TABLE 1. Correlations between hemodialysis indicators and urea concentration and the IPIS scale factors.

\begin{tabular}{|c|c|c|c|c|c|c|c|c|}
\hline \multirow{2}{*}{ IPIS scale factors } & \multicolumn{2}{|c|}{$\mathrm{Kt} / \mathrm{V}$} & \multicolumn{2}{|c|}{ URR ratio } & \multicolumn{2}{|c|}{ Urea before HD } & \multicolumn{2}{|c|}{ Urea after HD } \\
\hline & $\mathrm{r}$ & $\mathrm{p}$ & $\mathrm{r}$ & $\mathrm{p}$ & $\mathrm{r}$ & $\mathrm{p}$ & $\mathrm{r}$ & $\mathrm{p}$ \\
\hline Loss of motivation to carrying out specific activities & 0.07 & 0.429 & 0.10 & 0.262 & $0.39 *$ & 0.020 & 0.29 & 0.091 \\
\hline Mental sphere destruction & -0.09 & 0.327 & 0.00 & 0.964 & $0.50 * * *$ & 0.002 & $0.36^{*}$ & 0.034 \\
\hline Physical sphere destruction & 0.07 & 0.444 & 0.08 & 0.374 & $0.34 *$ & 0.047 & 0.21 & 0.216 \\
\hline Pessimism & 0.04 & 0.692 & 0.04 & 0.650 & $0.40^{*}$ & 0.017 & 0.26 & 0.130 \\
\hline Being a burden to others & -0.04 & 0.627 & 0.04 & 0.658 & -0.04 & 0.82 & -0.01 & 0.933 \\
\hline Loss of control over the illness & 0.15 & 0.085 & $0.20 *$ & 0.024 & $0.34 *$ & 0.047 & 0.19 & 0.269 \\
\hline General result & 0.04 & 0.642 & 0.10 & 0.253 & $0.42 *$ & 0.012 & 0.28 & 0.101 \\
\hline
\end{tabular}

* correlation significant at $\mathrm{p}<0.05$

$* * *$ correlation significant at $\mathrm{p}<0.005$

TABLE 2. Correlations between the indicators of hemodialysis dose and the Brief-IPQ scale.

\begin{tabular}{|c|c|c|c|c|c|c|c|c|}
\hline \multirow{2}{*}{ Brief-IPQ item } & \multicolumn{2}{|c|}{$\mathrm{Kt} / \mathrm{V}$} & \multicolumn{2}{|c|}{ URR ratio } & \multicolumn{2}{|c|}{ Urea before HD } & \multicolumn{2}{|c|}{ Urea after HD } \\
\hline & $\mathrm{r}$ & $\mathrm{p}$ & $\mathrm{r}$ & $\mathrm{p}$ & $\mathrm{r}$ & $\mathrm{p}$ & $\mathrm{r}$ & $\mathrm{p}$ \\
\hline Consequences & 0.14 & 0.122 & 0.06 & 0.546 & 0.10 & 0.586 & 0.10 & 0.551 \\
\hline Timeline & 0.11 & 0.22 & 0.16 & 0.083 & -0.12 & 0.486 & -0.12 & 0.487 \\
\hline Personal control & -0.04 & 0.633 & -0.03 & 0.732 & $-0.37 *$ & 0.028 & -0.22 & 0.201 \\
\hline Treatment control & 0.09 & 0.324 & 0.04 & 0.673 & 0.01 & 0.932 & 0.04 & 0.807 \\
\hline Identity & -0.05 & 0.555 & -0.09 & 0.303 & 0.04 & 0.826 & 0.00 & 0.981 \\
\hline Concern & 0.10 & 0.278 & 0.04 & 0.65 & 0.33 & 0.052 & 0.27 & 0.122 \\
\hline Understanding & -0.03 & 0.722 & -0.04 & 0.67 & -0.21 & 0.221 & -0.14 & 0.43 \\
\hline Emotional response & $0.19^{*}$ & 0.036 & 0.16 & 0.087 & 0.17 & 0.332 & -0.01 & 0.973 \\
\hline
\end{tabular}

* correlation significant at $\mathrm{p}<0.05$

TABLE 3. Correlations between indicators of hemodialysis and concentrations of urea and BSSS scale items.

\begin{tabular}{|c|c|c|c|c|c|c|c|c|}
\hline \multirow{2}{*}{ BSSS scale item } & \multicolumn{2}{|c|}{$\mathrm{Kt} / \mathrm{V}$} & \multicolumn{2}{|c|}{ URR ratio } & \multicolumn{2}{|c|}{ Urea before HD } & \multicolumn{2}{|c|}{ Urea after HD } \\
\hline & r & $\mathrm{p}$ & r & $\mathrm{p}$ & $\mathrm{r}$ & $\mathrm{p}$ & r & $\mathrm{p}$ \\
\hline Perceived Available Emotional Support & -0.03 & 0.71 & 0.02 & 0.783 & 0.08 & 0.656 & 0.05 & 0.77 \\
\hline Perceived Available Instrumental Support & -0.10 & 0.287 & -0.07 & 0.463 & 0.09 & 0.619 & 0.06 & 0.714 \\
\hline Need for Support & 0.11 & 0.244 & 0.08 & 0.364 & $0.36^{*}$ & 0.032 & 0.30 & 0.084 \\
\hline
\end{tabular}

* correlation significant at $\mathrm{p}<0.05$ 
limited correlations between different aspects of perceiving ESRD and the biomarkers, and between indicators of treatment adequacy and survival time. Work has shown that the belief in treatment effectiveness in the IPQ-R scale is connected with the indicator of survival time among patients maintained on hemodialysis $[7,8]$. On the other hand, there are no statistically significant correlations between indicators of dialysis adequacy and the perception of ones' own disease [4]. Our research found the presence of some, although relatively weak, correlations between the perception of the disease through the prism of the belief on the loss of control of ESRD and its negative impact on the emotional state, and the parameters of dialysis adequacy $\mathrm{Kt} / \mathrm{V}$ and URR. A significantly larger number of correlations with various aspects of disease perception was noted in relation to the level of urea measured before HD. This biomarker showed a significant relationship with almost all IPIS scale items and with the item of the Brief-IPQ expressing the conviction on being in control of ones' own disease. It is worth underlining that the existence of a connection between high level of urea before hemodialysis and the subjective conviction of the patient on having lost self-control over the illness was found in the matrix of correlation of both the BriefIPQ and the IPIS scale items. This observation is important, as it has been shown in prospective studies based on research conducted using the IPQ-R scale, that there is a relative stability as the disease progresses, of the factor expressing the belief of the patient's ability to self-regulate the disease [6]. Medical literature has also demonstrated the usefulness of $\mathrm{Kt} / \mathrm{V}$ and URR in evaluating the effectiveness of dialysis, and in using this indicator for predicting prognosis in patients maintained on hemodialysis [18]. It seems, however, that the dialysis adequacy indicators are not significant predictors of the patients' on HD psychosocial status. Far greater importance in this regard must be applied to the urea level determined before hemodialysis. This observation is reinforced by the identified (in this study) correlation between this biomarker and the need of social support. Patients maintained on hemodialysis in the course of ESRD, perceive their illness in an increasingly more negative light, as well as exhibit a greater need for social support, when they show higher levels of urea in their blood serum before hemodialysis. It must be noted that previous studies have underlined the importance of social support as one of the factors counteracting the occurrence of depressive syndromes [10]. Furthermore, these show correlation between the degree of social support, with fewer annual hospitalizations [11] and with the survival time of patients on hemodialysis [12].

\section{CONCLUSIONS}

1. The need for social support does not correlate with dialysis adequacy indicators.

2. The level of urea marked before hemodialysis exhibits an interdependence with psychological determinants of perception of ones' own illness and degree of social support. a) Patients who had a higher urea concentration before hemodialysis perceived their own illness as more bothersome. b) Patients characterized by higher values of urea concentration exhibited a greater need for social support.

3. Higher values of urea reduction (URR) are associated with the individual patient's belief on having lost control over their illness.

\section{REFERENCES}

1. Cukor D, Cohen SD, Peterson RA, Kimmel PL. Psychosocial aspects of chronic disease: ESRD as a paradigmatic illness. J Am Soc Nephrol. 2007;18(12):3042-55.

2. Fowler C, Baas LS. Illness representations in patients with chronic kidney disease on maintenance hemodialysis. Nephrol Nurs J. 2006;33(2):173-4, 179-86.

3. Chilcot J, Wellsted D, Farrington K. Illness representations are associated with fluid non-adherence among hemodialysis patients. J Psychosom Res. 2010;68(2):203-12.

4. Kim Y, Evangelista LS. Relationship between illness perceptions, treatment adherence, and clinical outcomes in patients on maintenance hemodialysis. Nephrol Nurs J. 2010;37(3):271-80.

5. Chilcot J, Norton S, Wellsted D, Farrington K. The factor structure of the Revised Illness Perception Questionnaire (IPQ-R) in end-stage renal disease patients. Psychol Health Med. 2012;17(5):578-88.

6. Tasmoc A1, Hogas S, Covic A. A longitudinal study on illness perceptions in hemodialysis patients: changes over time. Arch Med Sci. 2013;9(5):831-6.

7. van Dijk S, Scharloo M, Kaptein AA, et al. NECOSAD Study Group. Patients' representations of their end-stage renal disease: relation with mortality. Nephrol Dial Transplant. 2009;24:3183-5.

8. Chilcot J, Wellsted D, Farrington K. Illness perceptions predict survival in haemodialysis patients. Am J Nephrol. 2011;33:358-63.

9. Drążkowski D, Cierpiałkowska L. Zależność/niezależność od pola a wsparcie społeczne w kontekście stresu. Psychol Qual Life. 2013;12(1):29-41.

10. Khalil AA, Abed MA. Perceived social support is a partial mediator of the relationship between depressive symptoms and quality of life in patients receiving hemodialysis. Arch Psychiatr Nurs. 2014;28(2):114-8.

11. Plantinga LC, Fink NE, Harrington-Levey R, et al. Association of social support with outcomes in incident dialysis patients. Clin J Am Soc Nephrol. 2010;5(8):1480-8.

12. Untas A, Thumma J, Rascle N, et al. The associations of social support and other psychosocial factors with mortality and quality of life in the dialysis outcomes and practice patterns study. Clin J Am Soc Nephrol. 2011;6(1):142-52.

13. Daugirdas JT. Second generation logarithmic estimates of singlepool variable volume Kt/V: an analysis of error. J Am Soc Nephrol. 1993;4(5):1205-13.

14. Sak J. Wielowymiarowość postrzegania choroby w kontekście przekonań zdrowotnych i poczucia sensu życia: rozprawa habilitacyjna. Lublin: Jarosław Sak; 2013.

15. Broadbent E, Petrie KJ, Main J, Weinman J. The Brief Illness Perception Questionnaire. J Psychosom Res. 2006;60:631-7.

16. Leventhal H, Benyamini Y, Brownlee S, et al. Illness representations: Theoretical Foundations. In: K. J. Petrie, J .Weinman (eds). Perceptions of health and illness: Current research and applications. Amsterdam: Harwood Academic Publishers; 1997. p.19-45.

17. Łuszczyńska A, Kowalska M, Schwarzer R, Schulz U. Berlin Social Support Scales (BSSS) - Polish Version, 2002. [http://userpage.fu-berlin.de/ health/soc_pol.htm]

18. Sułowicz W. Praktyczne aspekty oceny jakości dializoterapii Forum Nefrolog. 2010;3(3):185-192.

\section{Corresponding author}

Department of Ethics and Human Philosophy,

Medical University of Lublin,

4/6 Staszica Str, 20-059 Lublin, Poland,

E-mail: jareksak@tlen.pl 